\title{
Autoimmune phenomena in treated and naive pediatric patients with chronic viral hepatitis
}

\author{
DANIELA PĂCURAR ${ }^{1,2}$, IRINA DIJMĂRESCU ${ }^{1,2}$, ADRIAN DIJMĂRESCU $^{3,4}$, \\ MIRELA PAVELESCU ${ }^{1,2}$, MIHAI ANDRONIE ${ }^{5}$ and CRISTINA BECHEANU ${ }^{1,2}$
}

\author{
${ }^{1}$ Department of Pediatrics, 'Grigore Alexandrescu' Emergency Children's Hospital, 011743 Bucharest; \\ Departments of ${ }^{2}$ Pediatrics and ${ }^{3}$ Radiology, 'Carol Davila' University of Medicine and Pharmacy, 020021 Bucharest; \\ ${ }^{4}$ Department of Radiology, Fundeni Clinical Institute, 022328 Bucharest; ${ }^{5}$ Department of Economic Sciences, \\ Faculty of Economic Sciences, Spiru Haret University, 030045 Bucharest, Romania
}

Received September 6, 2019; Accepted October 7, 2019

DOI: $10.3892 /$ etm.2019.8144

\begin{abstract}
Chronic viral hepatitis has been incriminated for inducing autoimmune events, but it is a known fact that interferon-based therapies also promote autoimmunity. We conducted an observational prospective study which included 114 pediatric patients with chronic viral hepatitis B and C. The patients were divided in 2 groups, the first group consisted of treatment-naive patients; the second group included patients who had received interferon-based therapy. We aimed to determine whether the ones who received treatment are more predisposed to developing autoimmune manifestations when compared to those naive. Fifty percent of the study group was found to have serological autoimmune phenomenon. Our research shows that the occurrence of the autoimmune phenomenon is delayed when the patient is treated with interferon-based regimens when compared to naive patients. Hence, even though interferon treatment has been reported to promote autoimmunity, the viruses themselves are more likely to induce the appearance of autoimmune markers over time in patients who do not receive treatment.
\end{abstract}

\section{Introduction}

Autoimmune events have been reported in both pediatric and adult patients with chronic hepatitis B and C (1-3). Even though autoimmune hepatitis and viral hepatitis are completely different entities, both are secondary to disturbances of the immune system (hepatitis viruses B and C are poorly cytopathic) and its failure to properly adjust the immune reaction towards hepatocytes $(4,5)$.

Correspondence to: Dr Irina Dijmărescu, Department of Pediatrics, 'Grigore Alexandrescu' Emergency Children's Hospital, 30-32 Iancu de Hunedoara Blvd, sector 1, 011743 Bucharest, Romania

E-mail: irinaandronie@yahoo.com

Key words: chronic hepatitis, viral hepatitis, pediatrics, autoimmunity, interferon therapy
Autoimmunity is defined as the loss of tolerance towards self-antigens, and its etiopathogenesis is still unknown. There are several factors considered to play a role in autoimmunity, such as genetic and environmental ones. Other factors, such as stress, are still being studied regarding their relationship with autoimmunity. Stress has been reported to be associated with onset and exacerbation of several autoimmune diseases. This is a new point of research, considering that stress has a major impact on modern lifestyle, and it is known to influence homeostasis and health $(6,7)$.

Persistence of hepatitis B or C viral infection depends on the interaction between the host's immune system and the virus. The destruction of the hepatocytes occurs when the immune reaction directed towards the hepatitis virus, essential for identifying the virus and subsequent viral clearance, generates an inflammatory reaction of the liver tissue through various mechanisms which up-regulate pro-inflammatory cytokines. Therefore, infected hepatocytes are destroyed by means of effector $\mathrm{T}$ cells. Concurrent, specific antibodies are generated by B cells in order to neutralize the virus. Previous research has shown that both viruses (hepatitis B virus and hepatitis C virus) possess the ability to escape the innate immune system, but a higher rate of persistence has been reported for the hepatitis $\mathrm{C}$ virus because it has the ability to escape the adaptive immunity as well. The adaptive immunity is responsible of recognizing antigenic structures and is sustained by B and $\mathrm{T}$ cells. One of its most important features is long-term memory, providing a quick secondary response. The ability of the hepatitis $\mathrm{C}$ virus to escape adaptive immunity resides in its high mutation rate (5).

Interferon treatment, which is widely used for treating chronic viral hepatitis, has also been incriminated in inducing autoimmunity (3). Interferon-based treatment is more advantageous than new therapies (nucleotide/nucleoside analogues) for chronic hepatitis B as it can provide immune-mediated control in many cases after only one year. Nucleotidic/nucleozidic analogues require long-term treatment courses and even though virological suppression is achieved in almost all patients, AgHBs clearance is low. Recently, a new strategy was approached by adding pegylated interferon in patients 
Table I. Autoimmune markers to determine the autoimmune phenomena.

Patients (number and percent)

\begin{tabular}{lrr} 
Autoimmune markers & $\mathrm{N}$ & $\%$ \\
\cline { 2 - 3 } No autoimmune markers & 57 & 50 \\
Autoimmune phenomena & 57 & 50 \\
Positive markers & 5 & 4.39 \\
Circulating immune complexes & 10 & 8.77 \\
Cryoglobulins & 1 & 0.88 \\
Cryoglobulins, C4 complement fraction & 4 & 3.51 \\
Cryoglobulins, circulating immune complexes & 3 & 2.63 \\
ANA & 2 & 1.75 \\
ANA, circulating immune complexes & 12 & 10.53 \\
Rheumatoid factor & 3 & 2.63 \\
Rheumatoid factor, circulating immune complexes & 8 & 7.02 \\
Rheumatoid factor, cryoglobulins & 2 & 1.75 \\
Rheumatoid factor, cryoglobulins, circulating immune complexes & 1 & 0.88 \\
LKM1, C4 complement fraction & 1 & 0.88 \\
LKM1, ANA & 1 & 0.88 \\
ASMA & 2 & 1.75 \\
ASMA, circulating immune complexes & 2 & 1.75 \\
ASMA, cryoglobulins & 114 & 100 \\
Total number of patients & & \\
\hline
\end{tabular}

previously treated with nucleosidic/nucleotidic analogues in order to speed the clearance of AgHBs (8).

Children with chronic viral hepatitis $\mathrm{B}$ are often in an immune tolerant state, but there is not enough data on how or if they should be treated is this phase of the disease. An association of interferon and lamivudin was reported to improve the rates of undetectable viremia and 'e' seroconversion in these patients (9). Positive antinuclear antibodies, anti-smooth muscle antibodies, circulating immune complexes and rheumatoid factor were often reported in patients with chronic viral hepatitis $\mathrm{B}$ and $\mathrm{C}$, but occurrence of autoimmune diseases did not appear to be correlated with the hepatitis $\mathrm{B}$ or $\mathrm{C}$ virus infection (10).

The present study assessed the autoimmune phenomena associated to pediatric chronic hepatitis B and $\mathrm{C}$ and whether the risk for autoimmune events is higher in patients who have received interferon treatment.

\section{Patients and methods}

An observational prospective study was conducted, which included 114 pediatric patients previously diagnosed with chronic viral hepatitis, 92 patients with chronic hepatitis B and 22 with chronic hepatitis $\mathrm{C}$. The patients presented to the Pediatrics Department of 'Grigore Alexandrescu' Emergency Children's Hospital in Bucharest, Romania, over a period of 40 months. Legal guardians of the patients signed an informed consent prior to inclusion in the study. The research was approved by the Ethics Committee of 'Grigore Alexandrescu' Emergency Children's Hospital - registration no. 8954/04.04.2018.
The subjects were divided in two groups - the first group included patients who had received treatment while the second group were treatment-naive. The patients who had been treated for chronic viral hepatitis were included in the study group at least 6 months after the medication was stopped (none of them was receiving treatment at the time of evaluation). The national treatment guide was followed: chronic viral hepatitis $B$ patients were treated with $\alpha-2 b$ interferon three times a week, while chronic viral hepatitis $\mathrm{C}$ patients were treated with pegylated-interferon once a week and daily ribavirin.

Several laboratory tests were performed for each patient. Autoimmune markers were pursued annually, including cryoglobulins, circulating immune complexes, complement abnormalities, rheumatoid factor and non-organ specific autoantibodies - antinuclear antibodies (ANA), anti-smooth muscle antibodies (ASMA), anti-liver kidney microsomal antibodies (LKM1).

Microsoft Excel was used to organize the data, while SPSS Kaplan-Meier survival curves were applied to evaluate the influence of treatment and period of time needed for the occurrence of the autoimmune phenomenon in these patients.

\section{Results}

One hundred and fourteen patients were enrolled, all of them previously diagnosed with hepatitis $\mathrm{B}$ or $\mathrm{C}$ viral infection. The age of the patients ranged from 18 months to 18 years, mean age 9 years with a standard deviation of 4.9. In all patients we identified the mother to be chronically infected with 
Table II. Median time until the autoimmune manifestations occurred.

\begin{tabular}{|c|c|c|c|c|}
\hline \multirow[b]{3}{*}{$\begin{array}{l}\text { Interferon (standard/ } \\
\text { pegylated) treatment }\end{array}$} & \multicolumn{4}{|c|}{ Median for survival time } \\
\hline & \multicolumn{2}{|c|}{ Median } & \multicolumn{2}{|c|}{$\begin{array}{l}95 \% \text { Confidence } \\
\text { interval }\end{array}$} \\
\hline & Estimate & $\begin{array}{l}\text { Standard } \\
\text { error }\end{array}$ & $\begin{array}{l}\text { Lower } \\
\text { bound }\end{array}$ & $\begin{array}{l}\text { Upper } \\
\text { bound }\end{array}$ \\
\hline Yes & 158,000 & 17,717 & 123,275 & 192,725 \\
\hline No & 71,000 & 15,131 & 41,343 & 100,657 \\
\hline Overall & 120,000 & 18,107 & 84,510 & 155,490 \\
\hline
\end{tabular}

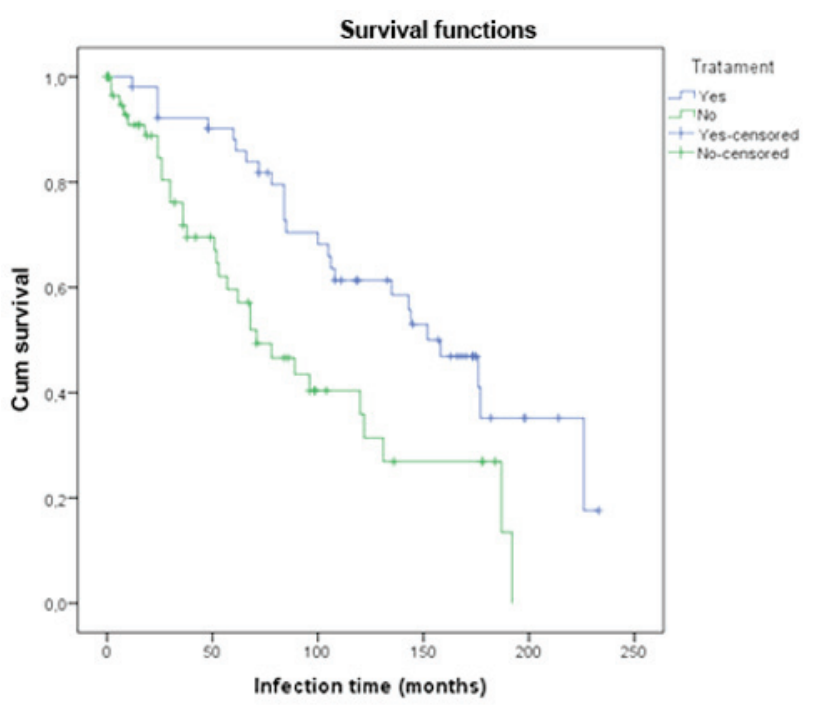

Figure 1. Kaplan-Meier survival curves.

hepatitis $\mathrm{B}$ or $\mathrm{C}$ virus, so we considered that the infection was transmitted vertically. Regarding gender, male to female ratio was 1.23 .

No clinically overt autoimmune manifestations were identified, but serological evidence of autoimmunity was found in $50 \%$ of the patients at some point during follow-up. Forty-six percent of patients included in the study group had previously received treatment, of them $50 \%$ were subsequently identified with autoimmune phenomena. Fifty-four percent of the patients were treatment-naive, and $50 \%$ of them presented autoimmune manifestations.

Regarding the markers that defined the autoimmune phenomenon, 31 patients were defined by only one positive marker, 24 had two simultaneous positive autoimmune markers, and further 2 had three simultaneous positive markers. The markers that determined the autoimmune phenomenon are listed in Table I.

We found that the probability of identifying autoimmune manifestations increased the longer the patient was chronically infected. For patients who had received treatment the autoimmune markers were identified after a longer period of time when compared to the group who had not been treated. At $\sim 190$ months, in the treatment group the probability of the
Table III. Comparison between the two curves.

\begin{tabular}{|c|c|c|c|}
\hline & \multicolumn{3}{|c|}{ Overall comparisons } \\
\hline & Chi-square & df & Sig. \\
\hline Log-rank (Mantel-Cox) & 9,397 & 1 & 0.002 \\
\hline Breslow (Generalized Wilcoxon) & 10,454 & 1 & 0.001 \\
\hline Tarone-Ware & 10,157 & 1 & 0.001 \\
\hline
\end{tabular}

occurrence of an autoimmune event was $\sim 65 \%$, while at the same time in the non-treatment group all the patients presented with autoimmune phenomena (Fig. 1).

The median for the time until the autoimmune manifestations occurred was 158 months in patients who had received treatment (with a 95\% confidence interval between 123.27 and 192.72 months) and 71 months in treatment-naive patients (with a $95 \%$ confidence interval between 41.34 and 100.65 months) (Table II). The fact that there is no overlap between the confidence intervals for the two compared groups shows that the reported difference is clinically significant.

The identified difference was found to be statistically significant - log-rank $\left(\chi^{2}=9.397, \mathrm{df}=1, \mathrm{P}=0.002\right)$, Breslow $\left(\chi^{2}=10.454, \mathrm{df}=1, \mathrm{P}=0.001\right)$, Tarone-Ware $\left(\chi^{2}=10.157, \mathrm{df}=1\right.$, $\mathrm{P}=0.001)$ (Table III). The log-rank test tends to focus more on the significance of the difference of the curves later in time. The Breslow test tends to look at what happens to the curves earlier in the time course, while the Tarone-Ware tests focuses on what happens at the middle of the time course. We report a statistically significant difference between the two compared curves at each tested time (Table III).

\section{Discussion}

Previous studies have linked interferon treatment to the occurrence of autoimmune markers. A research study conducted in 2014 by Pop et al (11) showed that antinuclear antibodies occurred in $13.79 \%$ of the pediatric patients with chronic viral hepatitis $\mathrm{B}$ who had received interferon therapy and had previously tested negative. For patients who had not received treatment the incidence for antinuclear antibodies was only $2.56 \%$. The difference was statistically significant $(\mathrm{P}=0.042)$. The same study states that the presence of these antibodies does not interfere with treatment response.

Other studies, which included adult patients, have shown that autoimmune markers were identified in $85 \%$ of the cases with chronic viral hepatitis $\mathrm{C}$ and $89 \%$ of the cases with chronic viral hepatitis $\mathrm{B}$. The serologic autoimmune phenomenon was reported in $74 \%$ of patients who had received short-term treatment ( $<30$ weeks) vs. $85 \%$ of the patients with long-time treatment (>50 weeks) (10). In our study, which included patients with both hepatitis $\mathrm{B}$ and hepatitis $\mathrm{C}$, autoimmune markers were identified in $50 \%$ of the cases, less than reported in previous research conducted on adult subjects, possibly secondary to the shorter time of evolution in children. According to our study, patients with chronic viral infection who have not received treatment will most likely develop autoimmune serological phenomenon earlier 
when compared to those who received interferon-based therapy.

The autoimmune phenomenon in chronic viral hepatitis still carries a high degree of uncertainty, especially in the pediatric field. Long-term studies have concluded that patients with chronic viral hepatitis $\mathrm{B}$ who do not receive treatment developed an antibody titer similar to that of patients who have received interferon treatment, but after a longer period of time (12). This contradicts the results of the present study. Our results stand by the idea that even though interferon-based therapies may induce autoimmunity, viruses themselves are more likely to induce the appearance of autoimmune markers over time in patients who do not receive treatment.

\section{Acknowledgements}

Not applicable.

\section{Funding}

No funding was received.

\section{Availability of data and materials}

The datasets generated and/or analyzed during the current study are available from the corresponding author on reasonable request.

\section{Authors' contributions}

DP contributed to designing the study, interpretation of data and revised the manuscript for important intellectual content. ID drafted the manuscript, acquired and contributed to interpretation of data. AD and MA contributed to drafting the manuscript, analyzed and interpreted the data. MP acquired the data and contributed to drafting the manuscript. CB contributed to designing the study and revised the manuscript for important intellectual content. All authors read and approved the final manuscript.

\section{Ethics approval and consent to participate}

Legal guardians of the patients signed an informed consent prior to inclusion in the study. The research was approved by the Ethics Committee of 'Grigore Alexandrescu' Emergency Children's Hospital (Bucharest, Romania) - registration no. 8954/04.04.2018.

\section{Patient consent for publication}

Not applicable.

\section{Competing interests}

The authors declare that they have no competing interests.

\section{References}

1. Hsieh MY, Dai CY, Lee LP, Huang JF, Chuang WL, Hou NJ, Lin ZY, Chen SC, Hsieh MY, Wang LY, et al: Antinuclear antibody titer and treatment response to peginterferon plus ribavirin for chronic hepatitis C patients. Kaohsiung J Med Sci 28: 86-93, 2012.

2. Muratori P, Muratori L, Verucchi G, Attard L, Bianchi FB and Lenzi M: Non-organ-specific autoantibodies in children with chronic hepatitis C: Clinical significance and impact on interferon treatment. Clin Infect Dis 37: 1320-1326, 2003.

3. Kansu A, Kuloğlu Z, Demirçeken F and Girgin N: Autoantibodies in children with chronic hepatitis B infection and the influence of interferon alpha. Turk J Gastroenterol 15: 213-218, 2004.

4. Lapierre $P$ and Lamarre A: Regulatory $T$ cells in autoimmune and viral chronic hepatitis. J Immunol Res 2015: 479703, 2015.

5. Piconese S, Cammarata I and Barnaba V: Viral hepatitis, inflammation, and cancer: A lesson for autoimmunity. J Autoimmun 95: 58-68, 2018.

6. Sharif K, Watad A, Coplan L, Lichtbroun B, Krosser A, Lichtbroun M, Bragazzi NL, Amital H, Afek A and Shoenfeld Y: The role of stress in the mosaic of autoimmunity: An overlooked association. Autoimmun Rev 17: 967-983, 2018.

7. Grigore O, Mihailescu AI, Solomon I, Boda D and Caruntu C: Role of stress in modulation of skin neurogenic inflammation. Exp Ther Med 17: 997-1003, 2019.

8. Viganò M, Grossi G, Loglio A and Lampertico P: Treatment of hepatitis B: Is there still a role for interferon? Liver Int 38 (Suppl 1): 79-83, 2018

9. Zhu S, Zhang H, Dong Y, Wang L, Xu Z, Liu W, Gan Y, Tang H, Chen D, Wang F, et al: Antiviral therapy in hepatitis B virus-infected children with immune-tolerant characteristics: A pilot open-label randomized study. J Hepatol 68: 1123-1128, 2018.

10. Orságová I, RoŽnovský L, Petroušová L, Konečná M, Kabieszová L, Martinek J, Kloudová A and Pavliska L: Investigation of autoimmunity markers during interferon alpha therapy of chronic hepatitis B and C - twenty years of experience. Klin Mikrobiol Infekc Lek 22: 61-67, 2016 (In Czech).

11. Pop TL, Stefănescu A, Samaşca G and Miu N: Clinical significance of the antinuclear antibodies in chronic viral hepatitis B in children. Clin Lab 60: 931-939, 2014.

12. Vajro $P$ and Veropalumbo $C$ : Treating children with HBeAg-positive chronic hepatitis B: No small accomplishment. Dig Liver Dis 46: 1064-1065, 2014.

This work is licensed under a Creative Commons Attribution-NonCommercial-NoDerivatives 4.0 International (CC BY-NC-ND 4.0) License. 